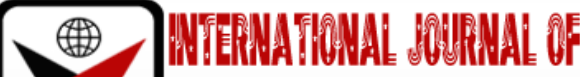

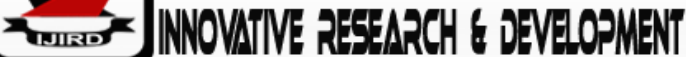

ISSN 2278 - 0211 (Online)

\section{Classroom Conversation: The Texture of Students' Contributions in Secondary School Mathematics}

\author{
Ibraheem Abiola Alabi \\ Ph.D. Student, Lagos State University, Nigeria
}

\begin{abstract}
:
This study is part of a larger study which explores the classroom conversation: the texture of students' contribution in secondary school Mathematics. For this part, it uses qualitative research design of two teaching strategies on Sequence and Series (Arithmetic \& Geometric Progression) in Mathematics. The qualitative method examines and interprets the observations on the texture of classroom conversation via the use of videotape and transcription. The target population for the study consists of all Senior Secondary Two (SS2) students in the public secondary schools in Lagos State. The study samples involve two SS2 students of public schools in the Badagry Local Government Area. In analysing qualitative data, descriptive statistics, mean, standard deviation, frequency counts, percentage bar chart are used. The findings of the research question show differences in the texture of the students' contributions in the treatment classroom and those in the conventional classroom. It is concluded that the texture of the students' contributions is highly more corresponding in the treatment classroom than in the conventional classroom and it is implicated towards their learning. It is however recommended that there is need to often organize seminars or workshops in training the teachers on the contemporary concepts in teaching and learning Mathematics.
\end{abstract}

Keywords: Texture, conversation, students' contributions, mathematics education

\section{Introduction}

The essential way to develop the students' inquiry includes their contributions as a yardstick for reforming their conceptual thinking in the Mathematics classroom. 'A key aspect of reform-oriented practice is choosing tasks that allow for conceptual thinking, reasoned justification and communication of mathematical ideas' (Brodie, 2008; p.4). Hiebert (2003) suggests three situations in which teachers might consider conveying information to students: (i) When students need conservative written notations; (ii) When students might not suggest or know any alternative methods presented by the teacher during consolidation and (iii) Also during consolidation, teachers may highlight the mathematical concepts rooted in the students' solutions.

Conversation spreads Mathematics in unfathomable and numerous ways through the students' participation in classroom discourse. Active participation in mathematical conversation is essential for the development of the students' mathematical understanding by explaining what they have done and benefited from listening to other students and describing how they approach a problem (ALIM, 2012). The students at times are excepted from classroom conversation for innumerable reasons if there is no regular way to guide the classroom conversation. It is on this latter remark that Baldinger and Louie (2014) design a guide for conversation that is grounded in the classroom observations which are organized along five dimensions:

- The Mathematics;

- Cognitive Demand;

- Access to Mathematical Content;

- Agency, Authority and Identity and

- Uses of Assessment.

It is the opinion of Baldinger and Louie that it will work best when it is used on the basis of having some shared experience of a definite lesson within the context of the content to definite students. In the classroom conversation, some students barely put their thoughts in words and this may be attributed to lack of self-reliance while others may be slow in learning and however require longer time in constructing their ideas. 'By expressing their ideas, the students provide their teacher with information about what they know and what they need to learn' (Anthony \& Walshaw, 2007, p. 72). More importantly, students' ideas and thinking need to be visible for a very robust Mathematics classroom to take place. look like:

It is on this view Fosnot (2005) describes how the classroom environment with the required conversation should

'... a mini- society - a community of learners engaged in mathematical activity, discourse and reflection. Learners must be given the opportunity to act as mathematicians by allowing, supporting and challenging their 'mathematising' of particular situations. The community provides an environment in which individual 
mathematical ideas can be expressed and tested against others' ideas....This enables learners to become clearer and more confident about what they know and understand.' (p. 10).

Many research studies over the years have been conducted across the globe on classroom conversation as implicated towards the students learning achievements. The review of various literatures has shown differences and similarities in the classroom conversations on the part of the students' contributions. In a book review of Hand (2012) on mathematical enquiry in order to add more depth to teaching mathematical reasoning in secondary school classrooms conducted by Brodie (2010), she reports that Brodie surveys the approaches and predicaments involved in promoting mathematical reasoning among students with opportunity to different types of resources for their mathematics learning. She further opines that Brodie offers a framework that stipulates the functioning of specific teacher's moves in response to different types of the students' contributions via first-hand accounts of teacher researchers who operate collaboratively with her to cultivate productive mathematical inquiry in their classrooms. The reviewer however notes that Brodie's account is deeply grounded in the details of moment-to-moment classroom interaction towards the activities and tensions that emerge within the complex Mathematics classroom. Thus, the reviewer focusses on how the structure and its developments of the study evolve into a strong description around the difficult work of teaching mathematical reasoning and the importance of developing more sophisticated and authentic tools for supporting the secondary Mathematics teachers. The reviewer sees the students' contributions in the classroom conversation as a direct pattern towards the teacher's talk.

In the research study of Şahin-Dogruer, Işıksal, and Koç (2015), they explore on a fifth grade Mathematics classroom through observation for a period of sixteen weeks that involves twenty lesson hours in total. The analysis is based on the students' learning as the main category, which is further divided into two sub-categories, including content and learning. The findings reveal that despite the recent reform efforts in school Mathematics in Turkey, the teachercentred instruction continues to be the dominating instructional method. Although the results do not meet the assumptions of discursive classroom at all, the study concludes through observing the classroom practices and argues that Mathematics teachers try to make connections between mathematical content and other disciplines where they try to give examples from real-world situations and encourage the students in that way.

In the research study of Taylor and Parsons (2011), they aim at improving the students' engagement in the classroom. The study focuses on how to work in the area of the students' commitment that is seen to have grown in a number of ways which include change from focusing upon the disengaged students to the engaged learners. The study concludes that change seems crucial and promises to organize how the study of the students' engagement will be carried out in the future.

Brodie (2007) investigates on teaching with conversations: beginnings and endings. The paper focuses on two important phases of mathematical conversations: beginnings and endings though it develops teaching approaches in many countries to support the students' conversations about their mathematical thinking. The analysis suggests that the ending conversations may be more difficult than beginning them, e.g., two teachers may successfully begin and maintain conversations but struggle to find the right moment and ways in which to end them. This suggests that the teachereducators might want to work with the teachers on how to pull the threads of a conversation together to ensure successful resolution.

Meanwhile, the students' contributions research studies which are conducted by Brodie (2008) focus on a teacher's changing practice in the context of curriculum change in South Africa. The study uses a range of analytic tools to indicate that his pedagogy is responsive to the students and enacts a number of key aspects of the new curriculum. The paper reveals that the key issue for teaching in the classroom is the students' very weak mathematical knowledge which constrains the teaching and is made visible by the teacher's approaches. The paper also argues that there are difficulties in the concepts of teacher change and the teacher should take into consideration the interaction between the learners' knowledge and the pedagogy provided the existing divides among the rich and poor contexts are not being aggravated.

However, the researcher adopts the Brodie's (2008) analytical framework for this study. This analytical framework has been used in the classroom conversation over the years and is both similar to and different from other existing contexts of analytical framework. Brodie's (2008) analytical framework is built upon Brodie' (2004) where the students' contributions are not explored in the classroom interaction. Brodie (2008) looks into when the teachers go beyond traditional teaching and actively engage with the students' ideas in order to develop conceptual links, promote discussion and develop mathematical reasoning with which students are often confronted by a range of the students' contributions. These contributions might be correct, incorrect or partially correct, well or poorly expressed, relevant or not relevant to the task or discussion, and productive or unproductive for further conversation and development of mathematical ideas. The students' contributions coding system is categorized as follows:

- Basic Error (BE): It is the students' contributions to the teacher's utterance in the classroom as an error not expected at the specific grade level.

- Appropriate Error (AE): It is the students' contributions to the teacher's utterance in the classroom as an incorrect contribution expected at the specific grade level towards the given task.

- Missing Information (MI): It is the students' contributions to the teacher's utterance in the classroom as correct but incomplete information and occurs when a student presents some of the information required by the task, but not all of it.

- Partial Insight (PI): It is the students' contributions to the teacher's utterance in the classroom to indicate students' grappling with an important idea which is neither complete nor correct contribution but shows an insight into the given task. 
- Complete Correct (CC): It is the students' contributions to the teacher's utterance in the classroom to providing an adequate answer to the given task.

- Beyond Task (BT): It is the students' contributions to the teacher's utterance in the classroom as the relatedness to the task of the lesson which goes beyond the immediate task and/or makes some interesting connections between ideas.

- Other (0): It refers to the students' contributions not in the category aforementioned.

\section{Statement of the Problem}

Many researchers over the years have explored different teaching strategies towards effective students' learning. Yet various challenges emanate in the Mathematics discourse. The implication here is that the use of the various strategy has only been used to replace the conventional approach of teaching but not taking into cognizance the conversation in delivering instruction to the students. Essentially, many researchers have worked on classroom conversation and reported that it is effective on learning as it drives the students thinking towards identifying and understanding concepts in the Mathematics classroom (Chauraya \& Brodie, 2018; Berger \& Bowie, 2012; Chitera, Kufaine, Jumbe \& Nhlema, 2012; Sfard, 2008; Brodie, 2008; Brodie, 2004).

Taylor (2017) opines that a good reflection of classroom conversation can only work if the teachers take and consider the time to respond to the students' entries while offering words of encouragement to the learners. However, classroom conversation is of great importance to classroom interaction and the aftermath has prompted many researchers to explore and see what value it adds to the teaching environment. For instance, Brodie (2008) studies students' contributions which reveal the involvement of student-student interaction to a large extent in the Mathematics classroom. It is against this background that the researcher explores the classroom conversation: the texture of the students' contributions in the secondary school Mathematics.

\section{Purpose of the Study}

The researcher explores the classroom conversation: the texture of the students' contributions in the secondary school Mathematics. It is the belief of the researcher that the students' participation in the classroom has the potentials of providing a panacea for their learning difficulties in Mathematics.

\section{Research Question}

What is the difference in the students' contributions in the treatment classroom and those in the conventional classroom?

\section{Research Method}

The researcher employs a qualitative approach in the conduct of the study. 'There has been a growing trend in the Mathematics education for researchers to use qualitative approaches' (Sharma, 2013; p.50). This phenomenal enquiry about all the factors involved in the research study gives a detailed account of what transpires in the real realm situation. The researcher uses a case study tradition of qualitative research design as folklore for describing the texture of the teacher's utterances in the Mathematics classroom influence students learning. The target population for the study consists of all the Senior Secondary Two (SS2) students in the public secondary schools in Lagos State. The choice of SS2 as population for the study is because the selected concept for students was on SS2 scheme of work. The topic is basically on the Sequence and Series concepts in Mathematics as the main concepts of the study. The accessible population is understudied based on the quantitative data obtained from the sample of the SS2 students of Lagos State.

The study sample involves two non-equivalent (intact) classes of the Senior Secondary Two (SS2) students designated as the treatment and control groups of public schools in the Badagry Local Government Area, Agboju District V in Lagos State. Both classes are mixed with male and female students and comparable numbers of students (60 in the treatment group and 54 in the control group) randomly picked from the population.

\section{Results}

The research question asked is: what is the difference in the students' contributions in the treatment classroom and those in the conventional classroom? In the consideration of this question, the classroom data, that is, the video tapes of lessons from the treatment and control groups are analysed using the Brodie's (2008) categories as presented in chapter two. To begin with, the researcher identifies and codes the students' contributions which are either correct or wrong as Basic Error, Appropriate Error, Missing Information, Partial Insight, Complete Correct, Beyond Task And Other. The rigorous process undertaken in doing this is explained in chapter three of this thesis. The analysis of the students' contributions shows that 455 students' contributions and 467 students' contributions are recorded in both the treatment and the control groups respectively. These contributions are recorded with the same numbers of lessons and minutes as reported in the study. The proportion of the students' contributions that is Basic Error, Appropriate Error, Missing Information, Partial Insight, Complete Correct, Beyond Task and Other is then computed and converted into percentages and presented in the table 1 and the figure 1 for the treatment and control groups.

It is, therefore, necessary to make a note of attention at this stage. The researcher looks into the difference of the students' contributions in the treatment and control groups in order to discover which among the students' contributions is predominant and has the texture of effective learning in the Mathematics classroom (see the table 1 and the figure 1). In the next few paragraphs, a comparison of the distribution of these contributions in the treatment and control groups is presented to explicate on the difference in the texture of the students' contributions in the think-pair-share Mathematics 
classroom (treatment) and that in the conventional classroom (control). The table 1 below shows the distribution of the students' contributions across all the four lessons each in both the treatment and control groups.

\begin{tabular}{|c|c|c|}
\hline Move & Treatment & Control \\
\hline Basic Error & $0(0 \%)$ & $5(1 \%)$ \\
\hline Approriate Error & $0(0 \%)$ & $2(0.4 \%)$ \\
\hline Missing Information & $26(6 \%)$ & $9(2 \%)$ \\
\hline Partial Insight & $60(13 \%)$ & $2(0.4 \%)$ \\
\hline Complete Correct & $239(52 \%)$ & $268(57 \%)$ \\
\hline Beyond Task & $18(4 \%)$ & $6(1 \%)$ \\
\hline Other & $113(25 \%)$ & $175(37 \%)$ \\
\hline Total & 456 & 467 \\
\hline
\end{tabular}

Table 1: Students' Contributions in the Treatment and Control Groups across All the Lessons

Importantly, the revelation in the table 1 is the characteristics of these students' contributions in the treatment and control groups. The frequency count of the students' contributions in the control group shows more than in the treatment group. The texture of the students' contributions noted for BASIC ERROR and APPROPRIATE ERROR is not recorded at all for the treatment group but slightly recorded for the control group. The reasons for these findings may not be unconnected with the classroom environment in the treatment group where the classroom lesson is based on strategy. The students in the treatment group can at first interact and share their contribution with the pair before sharing with the whole class. This affords the students in the treatment group to be more enlightened and reduces their likelihood of sharing wrong answers. Meanwhile, the reverse is the case in the control group. This frequency count of the students' contributions is converted to percentage value as indicated in the table 1 . The percentage bar chart is computed to show more of the difference in the texture of the students' contributions in the treatment and control groups as shown in the figure 1 below.

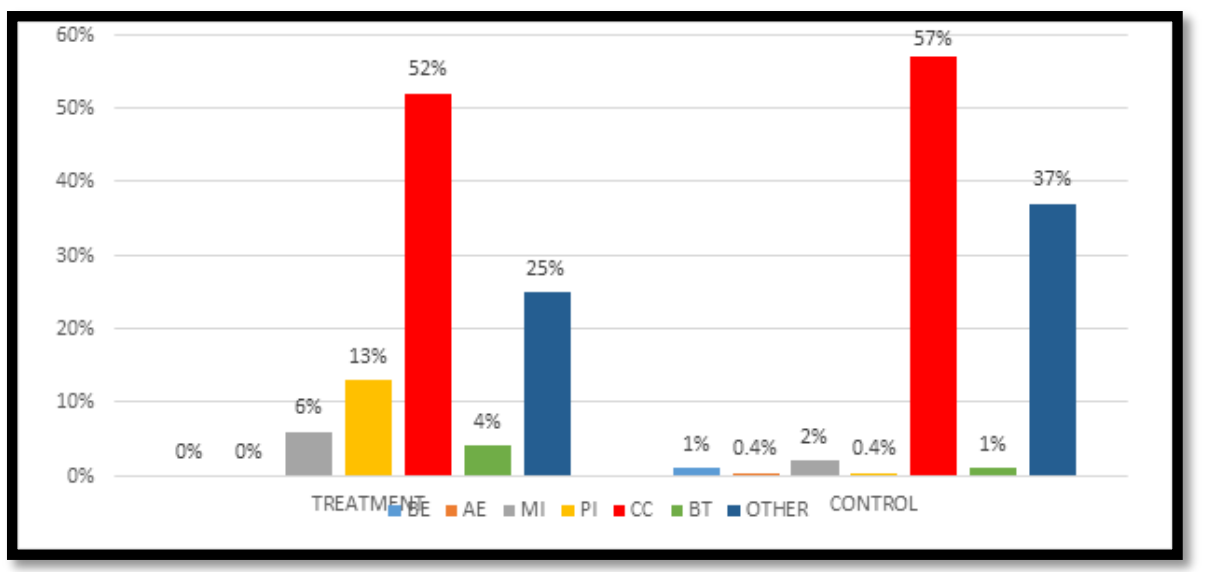

Figure 1: Students' Contributions in the Treatment and Control Groups

Considering the figure 1 above, showing the categories of the students' contributions that characterized the classroom students' contributions in both the treatment and control groups, the percentage value of the students' contributions is presented in the bar chart. This reveals the proportion of the students' contributions for all the lessons delivery in the treatment and control groups. The lessons in the treatment and control groups show that the students' contributions are predominantly CC in the treatment and control groups. The CC contribution is indicative of the acts of the students providing an absolute answer to the task in the treatment and control groups. Whatever the teacher's utterances in the treatment and control groups are, there is always a corresponding students' contribution which makes the classroom more interactive.

Meanwhile, it is noted that in comparison of the OTHER contribution, the students' contributions in the treatment and control groups have moderate proportions of $25 \%$ and $37 \%$ respectively. It is implicative that the OTHER contributions are seen in the treatment and control groups but largely in control group. The reasons for this may not be unconnected to the low students' participation in the classroom conversation in the control group where the students remain silent in most cases as evident in the OTHER contributions. In further description of this predominance of the students' contributions, an extract from one of the study transcripts of the treatment and control groups is examined as shown below. This extract is focused on the CC and OTHER contributions that are predominant as indicated in the table 1. In doing this, on the one hand, the researcher reflects on the treatment group extract and looks at the CC and OTHER contributions predominance in one of the transcripts. These extracts are as follows:

TG-L1-U14 Teacher: Well defined group is very important, well defined group; very, very important.

TG-L1-C13 Students: Silence 
TG-L1-U15 Teacher: This time around, we want to start up with a topic, Arithmetic Progression. But before then, I want to give an example of a sequence. For instance, when you write something like this (pointing to 2, 4, 6, . .) blah, blah ... is a what?

TG-L1-C14 Chorus: Sequence

TG-L1-U16 Teacher: Now when you have something like this (pointing to $2+4+6+\ldots$ )

TG-L1-C15 Chorus: Series.

TG-L1-U17 Teacher: It is called a ....

TG-L1-C16 Chorus: Series

TG-L1-U18 Teacher: This a sequence (pointing to 2, 4, 6, . . on the board), this is a series (pointing to

$2+4+6+\ldots$ on the board). Right now, we are going into a very topic, common series and sequence are (not clear) ... lots of topic. We have arithmetic progression; we have the ...

TG-L1-C17 Chorus: Geometric Progression.

TG-L1-U19 Teacher: But for this class, I want to quickly take a look at Arithmetic ...

TG-L1-C18 Chorus: Progression.

TG-L1-U20 Teacher: Right now, I am going to write examples on the board and solve them. Then, I am going to group you (working in pair). Then, I will give you classwork or I will give you an exercise which you have to brainstorm; you work together as a team (each pair). Then any of the pair will produce the result and later share their result with the whole class.

TG-L1-C19 Students: Silence

TG-L1-U21 Teacher: Now before we proceed on this example, I want us to know that these (she writes 9 ,

$12,15,18, .$.$) These are what?$

TG-L1-C20 Students: Silence

TG-L1-U22 Teacher: These are what?

TG-L1-C21 Chorus: Sequence

TG-L1-U23 Teacher: Now, from this sequence we have, the first term is what?

TG-L1-C22 Chorus: Nine

It is indicated from the extract above that the texture of the students' contributions is being mostly characterized with the CC contribution. The students' contributions are providing absolute responses towards the given task as evident in the lines TG-L1-C14, TG-L1-C15, TG-L1-C16, TG-L1-C17, TG-L1-C18, TG-L1-C121 and TG-L1-C22. Similarly, it is also as evident in the lines TG-L1-C13, TG-L1-C19 and TG-L1-C20 for OTHER contributions which show an undecided status of the students-to-teacher utterances. It indicates the acts of the students providing absolute answer to the classroom tasks and remaining silent at a point when in doubt which are evident of the CC and OTHER contributions respectively. This shows that for some period of time in the classroom conversation, the texture of the students' contribution is greatly associated with the acts of providing the correct answers and partially associated with undecided decisions. By so doing, the teacher receives a good feedback from the students and that prompts her to do more impacting knowledge during the classroom conversation. On the other hand, the researcher reflects on the control group extract and looks at the CC and OTHER contributions predominance in one of the transcripts. These extracts are as follows:

CG-L4-U43 Teacher: Find the sum of the following GP two plus six plus eighteen plus fifty-four plus (pause)...to what? ... to (pause)... plus one thousand, four hundred and fifty-eight as far as the eightieth term ...

CG-L4-C41 Students: Silence

CG-L4-U44 Teacher: Here we have our a is what?

CG-L4-C42 Students: Silence

CG-L4-U45 Teacher: Two, our last term is what?

CG-L4-C43 Students: Silence

CG-L4-U46 Teacher: One thousand, four hundred and fifty-eight. There is one unknown, we have our ratio six over two, that will give us what? Ehmm ...

CG-L4-C44 Chorus: Three ...

CG-L4-U47 Teacher: Three (pause) ... what? Our ratio is ...

CG-L4-C45 Chorus: Three

CG-L4-U48 Teacher: Then, there is something missing, number of term. number. Before we can go to find the sum, the first thing is to find what?

CG-L4-C46 Chorus: Number of term.

CG-L4-U49 Teacher: Number of term.

CG-L4-C47 Students: Silence

CG-L4-U50 Teacher: Therefore, we have to ..., our last term ... a times r raises to power n minus one.

What is our last term?

CG-L4-C48 Students: Silence

CG-L4-U51 Teacher: One thousand, four hundred and fifty-eight equal to (pause)..., ...a, give us what?

CG-L4-C49 Chorus: Two.

CG-L4-U52 Teacher: Multiply by ...

CG-L4-C50 Chorus: Three raise to power $\mathrm{n}$ minus one

CG-L4-U53 Teacher: Divide both sides by two. This (pointing 2 on the board) will go; we are having two in fourteen.

CG-L4-C51 Chorus: Seven. 
It is indicated from the extract above that the texture of the students' contributions is being mostly characterized with the CC contribution. The students' contributions are providing absolute responses towards the given task as evident in the lines CG-L4-C45, CG-L4-C46, CG-L4-C49, CG-L4-C50 and CG-L4-C51. Similarly, it is also as evident in the lines CG-L4C41, CG-L4-C42, CG-L4-C43, CG-L4-C47 and CG-L4-C48 for OTHER contributions which shows an undecided status of students to teacher utterances. It indicates the acts of students' providing absolute answer to the classroom task and remained silent at a point when in doubt which are evident of the CC and OTHER contributions respectively. This shows that for some period of time of the classroom conversation, the texture of the students' contribution is greatly associated with the acts of providing the correct answer and partially associated with undecided decisions. By so doing, the teacher receives a good feedback from the students and that prompts her to do more, impacting knowledge during the classroom conversation.

In general terms, the comparison of the difference in the texture of students' contributions is observed based on their record in the think-pair-share classroom and the conventional classroom. First, the BE contribution is not recorded at all in the treatment group but slightly recorded in the control group. The difference in the BE contribution represents $1 \%$ in favour of the control group over the treatment group. Second, the AE contribution is not recorded at all in the treatment group but rarely recorded in the control group. The difference in the AE contribution represents $0.4 \%$ in favour of the control group over the treatment group. Third, the MI contribution is more recorded in the treatment group than in the control group. The difference in the MI contribution represents $4 \%$ in favour of the treatment group over the control group.

Fourth, the PI contribution is more recorded in the treatment group than in the control group. The difference in the PI contribution represents $13 \%$ in favour of the treatment group over the control group. Fifth, the CC contribution is more recorded in the control group than in the treatment group. The difference in the CC contribution represents $4 \%$ in favour of the control group over the treatment group. Sixth, the BT contribution is more recorded in the treatment group than in the control group. The difference in the BT contribution represents 3\% in favour of the treatment group over the control group. Sixth, the OTHER contribution is more recorded in the control group than in the treatment group. The difference in the OTHER contribution represents $12 \%$ in favour of the control group over the treatment group.

Above all, this section of the study reveals some differences in the texture of the students' contributions in the treatment and control groups. It is observed that the students' contributions in the treatment and control groups are characterized with the CC and OTHER. The use of the think-pair-share strategy in the treatment group affords the students to make more contributions because of the strategy involved. These contributions are largely correct (PI, CC and BT contributions) representing 70\% of the students' contributions in the treatment group compared to 58\% of the students' contributions in the control group. Similarly, the wrong contributions (BE, AE and MI contributions) have the proportions of $6 \%$ and $3 \%$ in the treatment and control groups respectively. The remaining contributions are recorded for OTHER with the proportions of $25 \%$ and $37 \%$ in the treatment and control groups respectively. Thus, the texture of the students' contributions in the think-pair-share classroom is recorded for more correct and wrong contributions than in the control group while the OTHER contribution in the treatment group is recorded less than in the control group. In the meantime, the researcher's focus in the next section is on the students' learning achievement.

\section{Discussion of Findings}

The findings of this study reveal differences between the students' contributions in the think-pair-share classroom and those in the conventional classrooms. The students' contributions in the think-pair-share classroom are predominantly COMPLETE CORRECT. These quality students' contributions are found to be as a result of the responsive teacher's corresponding talk in the classroom conversation that is very directive to the students. This finding is in agreement with the position in the literature where change in the teacher's moves with high proportion of the COMPLETE CORRECT contributions in the classroom conversation is attributed to the directing pattern of the teacher's talk to the students (Hand, 2012; Brodie, 2008).

Similarly, the conventional classroom is also predominant with the COMPLETE CORRECT contributions as shown in the earlier chapter (see the table 4.3 and the figure 4.3). Since the teacher's utterances are predominant the corresponding students' contributions in the classroom are found to be adequate answer to the teacher's utterances. This finding buttresses the position in the literature where change in the teacher's moves with high proportion of the COMPLETE CORRECT contributions in the classroom conversation is attributed to the directing pattern of the teacher's talk to the students (Hand, 2012; Brodie, 2008).

Importantly, the students' contributions in the treatment and control groups in terms of providing an adequate answer to the given task are predominantly COMPLETE CORRECT in their contributions. In the case of the think-pair-share classroom, the students' contributions are basically to make meaningful impact and show their level of interaction. While in the control group, the students' contributions are basically to accept what the teacher is saying. Thus, the students in the think-pair-share classroom are more collaborated in their classroom activities while the students in the control group are without collaboration in their classroom activities.

\section{Conclusion}

The study explores the classroom conversation: the texture of the students' contributions in the secondary school Mathematics. From the findings of this study, it is concluded that the texture of the students' contributions is highly more corresponding in the treatment classroom than in the conventional classroom and it is implicated towards their learning. 


\section{Recommendations}

In consideration of the findings of this study, the following recommendations towards improvement are made:

- Education districts, schools, teachers and future researchers could benefit from this study and continue building on this research.

- Mathematics educators should spring up wide publicity of the urgency or needs for the classroom conversation to be taken into cognizance in the classroom.

- There is need to often organize seminars or workshops in training the teachers on the contemporary concepts in teaching and learning Mathematics.

- Professional associations like the Mathematical Association of Nigeria (MAN) should popularize the classroom conversation.

\section{References}

i. Accelerating Learning in Mathematics, ALIM. (2012). Helping Students to Participate in Learning Conversations. Accessed from http://nzmaths.co.nz/accelerating-learning. New Zealand Ministry of Education

ii. Anthony, G. \& Walshaw, M. (2007). Effective Pedagogy in Mathematics/Pāngarau: Best Evidence Synthesis Iteration [BES]. Wellington: Ministry of Education.

iii. Baldinger, E., \& Louie, N. (2014). TRU Math conversation guide: A tool for teacher learning and growth.

iv. Berger, M. \& Bowie, L. (2012). A Course on Functions for In-Service Mathematics Teachers: Changing Teachers' Discourse. Proceeding of Twentieth Annual Meeting of the Southern African Association for Research in Mathematics, Science and Technology Education.

v. Brodie, K. (2004). Working with Learner Contributions: Coding Teacher Responses. In D. E. McDougall \& J. A. Ross (Eds.), Proceedings of the 26th Annual meeting of the Psychology of Mathematics Education (North America), Volume 2 (pp. 689-697). Toronto: OISE/UT.

vi. Brodie, K. (2007), Teaching with conversations: Beginnings and endings. For the Learning of Mathematics $27,1$. FLM Publishing Association, Edmonton, Alberta, Canada

vii. Brodie, K. (2008) Describing Teacher Change: Interactions between teacher moves and Learner contributions. In J. F. Matos, P. Valero \& K. Yasukawa (Eds.). Proceedings of the Fifth International Mathematics Education and Society Conference. Lisbon.

viii. Chauraya, M. \& Brodie, K. (2018) Conversations in a professional learning community: An analysis of teacher learning opportunities in mathematics. Pythagoras - Journal of the Association for Mathematics Education of South Africa

ix. Chitera, N., Kufaine N, Jumbe G. \& Nhlema A. (2012). Local Languages and Mathematical Discourse: What Type? Proceeding of Twentieth Annual Meeting of the Southern African Association for Research in Mathematics, Science and Technology Education.

x. Fosnot, C. T. (2005). Constructivism revisited: Implications and reflections. The Constructivist, 16(1).

xi. Hand, V. (2012). Book Review: Adding depth to portraits of mathematical inquiry. Teaching mathematical reasoning in secondary school classrooms conducted by Brodie (2010) Educ Stud Math (2012) 79:149-155. D0I $10.1007 / \mathrm{s} 10649-011-9344-\mathrm{z}$

xii. Hiebert, J. (2003). Signposts for teaching mathematics through problem-solving. In Teaching Mathematics through problem solving: Pre-kindergarten Grade 6 Reston, VA: NCTM

xiii. Şahin-Doğruer, Ş., Işıksal, M. \& Koç, Y (2015). A Case Study on Mathematical Classroom Discourse in a Fifth Grade Classroom. Gaziantep University Journal of Social Sciences (http://jss.gantep.edu.tr) 14(1):299-322 ISSN: 13030094

xiv. Sfard, A. (2008). Thinking as Communicating: Human Development, the growth of discourses, and mathematising. New York: Cambridge

xv. Sharma, S. (2013). Qualitative Approaches in Mathematics Education Research: Challenges and Possible Solutions, Education Journal. Vol. 2, No. 2, pp.50-57. doi: 10.11648/j.edu.20130202.14

xvi. Taylor, S. R. (2017). Successful teacher practices for reducing Mathematics anxiety in secondary students

xvii. Taylor, L. \& Parsons, J. (2011). Improving Student Engagement. Current Issues in Education, 14(1). Retrieved from http://cie.asu.edu/ 